\title{
The effect of natural and artificial grass on sprinting performance in young soccer players
}

\author{
Vasileios Kanaras ${ }^{1,2}$, Thomas I. Metaxas ${ }^{1}$, , Athanasios Mandroukas ${ }^{1}$, Ioannis Gissis ${ }^{2}$, \\ Andreas Zafeiridis ${ }^{2}$, Christos S. Riganas ${ }^{1}$, Evaggelos Manolopoulos ${ }^{2}$, Vassilis Paschalis ${ }^{3,4}$, \\ Ioannis S. Vrabas ${ }^{2}$ \\ ${ }^{1}$ Department of Physical Education and Sports Sciences, Aristotle University of Thessaloniki, Thessaloniki, Greece \\ ${ }^{2}$ Department of Physical Education and Sports Sciences at Serres, Aristotle University of Thessaloniki, Greece \\ ${ }^{3}$ Department of Physical Education and Sports Sciences, University of Thessaly, Greece \\ ${ }^{4}$ Laboratory of Exercise, Health and Human Performance, Research Center, European University of Cyprus, Nicosia, Cyprus
}

\section{Email address:}

tommet@phed.auth.gr (T. I. Metaxas)

\section{To cite this article:}

Vasileios Kanaras, Thomas I. Metaxas, Athanasios Mandroukas, Ioannis Gissis, Andreas Zafeiridis, Christos S. Riganas, Evaggelos Manolopoulos, Vassilis Paschalis, Ioannis S. Vrabas. The Effect of Natural and Artificial Grass on Sprinting Performance in Young Soccer Players. American Journal of Sports Science. Vol. 2, No. 1, 2014, pp. 1-4. doi: 10.11648/j.ajss.20140201.11

\begin{abstract}
The sprint performance on natural and artificial grass of $5^{\text {th }}$ generation was assessed. Sixty eight young male soccer players, which were divided in two groups according to their age [children $(n=36 ; 12.1 \pm 0.5 y)$ and adolescents $(n=32$; $14.2 \pm 0.4 \mathrm{y})$ ], performed $30-\mathrm{m}$ sprint tests with and without handling the ball on natural and artificial grass. The performance was recorded during $0-10 \mathrm{~m}, 10-30 \mathrm{~m}$, and $0-30 \mathrm{~m}$ running distances. It was found that children were significantly faster during 0-10m running distance on the artificial compared to natural grass when handling the ball while adolescents revealed no differences in sprint performance between the surfaces irrespectively of the ball condition. In running distances 10-30m and $0-30 \mathrm{~m}$, children were significant faster in the artificial compared to the natural grass either with or without ball, while the adolescents were significantly faster in the artificial grass only without handling the ball. Children run faster on artificial than natural grass while adolescent soccer players are faster in artificial grass when they do not have to handle the ball. It is clear that children should be more careful when play soccer on artificial grass because the ball is moving faster and greater skill is needed in order to avoid injuries.
\end{abstract}

Keywords: Adolescent, Artificial, Children, Natural Grass, Sprint Ability, Turf

\section{Introduction}

Sprinting constitutes a multidimensional and complex motor skill, being probably the most significant physical element of performance in modern soccer. Numerous studies have reported that in a $60 \mathrm{~min}$ soccer game, young players completed over 30 maximal sprints (i.e. speed higher than $18 \mathrm{~km} / \mathrm{h}$ ), while the total distance covered during maximal sprints may reach 250m [1-3]. For this reason, coaches include at least two training sessions focusing on the improvement of maximal speed performance with and without handling the ball [4].

Traditionally, soccer games take place on natural grass; however, in many European countries, the use of artificial grass is continuously increased either for official soccer games or for training. Since 2005, UEFA and FIFA have approved the use of artificial grass of 3rd generation in their official tournaments $[5,6]$. The last few years' research has focused on technical aspects and the physical conditioning of soccer players when training or competing on artificial grass. Anderson et al. [7] compared technical characteristics of soccer players on two different surfaces (i.e. natural grass vs. $3^{\text {rd }}$ generation artificial grass) and was observed that players exhibited better technical skills on artificial compared to natural grass. Moreover, Di Michelle et al. [8] and Sassi et al. [9] reported that both heart rate and blood lactate were elevated when a game was performed on a $3^{\text {rd }}$ generation artificial grass compared to natural grass.

The widely used artificial grass led Meyers and Barnhill [10] to examine the frequency, the causes, and the severity of injuries compared to natural grass. It was found that, there is a greater chance for of epidermal injuries and muscle strains on artificial grass compare to natural grass 
[10] because of the greater fatigue potential of muscles [11], while the greater incidence of concussion and ligament tears on natural grass compared to the artificial grass may be related to the harder and drier surface [12]. Moreover, it was found that during a soccer game on artificial grass the mechanical load developed at the middle plantar portion and in the $5^{\text {th }}$ toe was significantly higher compared to natural grass [13].

An increasing number of young soccer players compete and/or train on artificial grass. However, there is no data available regarding the effect of artificial grass on sprint performance while controlling the ball compared to natural grass in soccer players of developmental ages. Thus, the purpose of this study was to compare the sprint performance of children and adolescent soccer players on natural grass and artificial grass of $5^{\text {th }}$ generation without or with handling the ball.

\section{Methods}

\subsection{Participants}

Sixty eight male children and adolescent soccer players participated in the present investigation (Table 1). All subjects participated regularly (i.e. 4-5 times/week) in soccer training or competitive matches. Participants were reported no injury of the lower limbs during the last year and they did not use any nutritional supplement. A written informed consent was provided by their parents after they were informed about all risks, discomforts, and benefits involved in the study. The procedures were in accordance with the 1975 Declaration of Helsinki, as revised in 2000, and approval was received from the institutional review board.

Table 1. Demographic characteristics of the children and the adolescents group (mean $\pm S D)$.

\begin{tabular}{llllll}
\hline & \multicolumn{2}{l}{$\begin{array}{l}\text { Children } \\
\text { n=36 }\end{array}$} & \multicolumn{4}{l}{$\begin{array}{l}\text { Adolescents } \\
\mathbf{n = 3 2}\end{array}$} \\
\hline Age (years) & 12.0 & \pm 0.5 & 14.0 & \pm 0.5 \\
Training age (years) & 5.5 & \pm 1.0 & 7.0 & \pm 1.5 \\
Body mass (kg) & 39.4 & \pm 6.1 & 57.1 & \pm 9.9 \\
High (cm) & 146 & \pm 7 & 165 & \pm 7 \\
\hline
\end{tabular}

\subsection{Procedures}

All measurements were conducted under field conditions on natural grass or artificial grass of 5th generation. Upon arrival the participants' body mass and height were measured on a digital height-weight scale (Seca, 703, Hamburg, Germany). Consequently, participants performed a standardized $25 \mathrm{~min}$ warm-up consisting of $5 \mathrm{~min}$ sub-maximal running, $5 \mathrm{~min}$ of stretching exercises, ball handling exercises for $5 \mathrm{~min}$, three repetitions of $15 \mathrm{~m}$ run-outs at approximately $90 \%$ of maximal speed, and 4 min of active recovery. Speed performance was assessed using a multidirectional $30 \mathrm{~m}$ sprint test. During the test, the participants had to run $10 \mathrm{~m}$ with maximal speed in a straight line $(0-10 \mathrm{~m})$ followed by a $10 \mathrm{~m}$ double change of direction right or left $(10-20 \mathrm{~m})$, and finished with a $10-\mathrm{m}$ maximal sprint in a straight line $(20-30 \mathrm{~m})$. The sprint performance was assessed in running distances $0-10 \mathrm{~m}$, $10-30 \mathrm{~m}$, and $0-30 \mathrm{~m}$ with the use of photocells (Newtest Powertimer, Finland) placed at the start, at $10 \mathrm{~m}$ and at $30 \mathrm{~m}$ marks. Each participant performed two efforts with and without handling the ball on the natural grass and the artificial grass while there was 5 min rest between the sprints. All efforts were randomized in respect to both conditions that is the ball handling and the surface of the field. During the trials, continuous verbal encouragement was provided to the players. All tests were performed on non-raining days and the wind speed not exceeding $1 \mathrm{~m} / \mathrm{s}$. The ambient temperature and the relative humidity during the testing days ranged from $20^{\circ}$ to $23^{\circ} \mathrm{C}$ and from 50 to $60 \%$, respectively.

\subsection{Statistical Analysis}

A 3 way ANOVA [age (children and adolescents) $\times$ grass (natural and artificial) $\times$ ball (with and without handling)] with repeated measures on field surface and ball condition was used for analyzing the performance for each running distance $(0-10 \mathrm{~m}, 10-30 \mathrm{~m}$, and $0-30 \mathrm{~m})$. Significant main effects were followed by Tukey post hoc tests to locate the significantly different means. All data are presented as means \pm SD and were analyzed by Statistica version 7.0 (StatSoft Inc., Tulsa, USA). The level of significance was set at $\alpha=0.05$.

\section{Results}

A significant age $\times$ ball $\times$ grass interaction was detected on sprint performance in distances $0-10 \mathrm{~m}$ (F1,66=2.47; $\mathrm{p}<0.001 ;$ Figure 1A), $10-30 \mathrm{~m} \quad(\mathrm{~F} 1,66=17.09 ; \mathrm{p}<0.001$; Figure $1 \mathrm{~B})$ and $0-30 \mathrm{~m}(\mathrm{~F} 1,66=17.37 ; \mathrm{p}<0.001$; Figure $1 \mathrm{C})$.

Pair-wise comparisons between the field surface conditions at $0-10 \mathrm{~m}$ running distance revealed that children when handling the ball are faster on artificial grass compared to natural grass $(\mathrm{p}<0.01 ;$ Fig $1 \mathrm{~A})$. In contrast, no differences in the performance at the same running distance were observed between artificial and natural grass of $0-10 \mathrm{~m}$ in adolescents irrespective of ball condition.

Regarding the running distance of 10-30m (Figure 1B) and $0-30 \mathrm{~m}$ (Figure $1 \mathrm{C}$ ), the performance in children was significantly better $(\mathrm{p}<0.01)$ on the artificial compared to the natural grass with or without handling the ball (Figure 1B and 1C). In adolescents, sprint performance was significantly better $(\mathrm{p}<0.01)$ on the artificial compared to the natural grass only without handling the ball.

The performance was better $(p<0.05)$ without handling the ball than handling the ball irrespectively of age and field surface while the adolescents were significantly faster $(p<0.05)$ compared to children irrespectively of field surface with or without handling the ball (Figure 1). 


\section{Discussion}

The main finding of this study is that sprinting performance is superior on artificial grass than natural grass in young soccer players. This superiority on artificial grass, however, is affected by age and handling or not a ball during the test. More specifically, children ran faster in $0-10 \mathrm{~m}$ running distance on the artificial grass compared to the natural grass while handling the ball. In the same running distance the field surface did not affect the performance of adolescents. Regarding the sprint performance in $10-30 \mathrm{~m}$ distance, children run faster on the artificial vs. the natural grass irrespective of handling or not the ball, whereas adolescents achieved better sprinting performance on the artificial vs. natural grass only without handling the ball. Overall, the adolescents run faster compared to the children irrespectively of field surface with or without handling the ball.
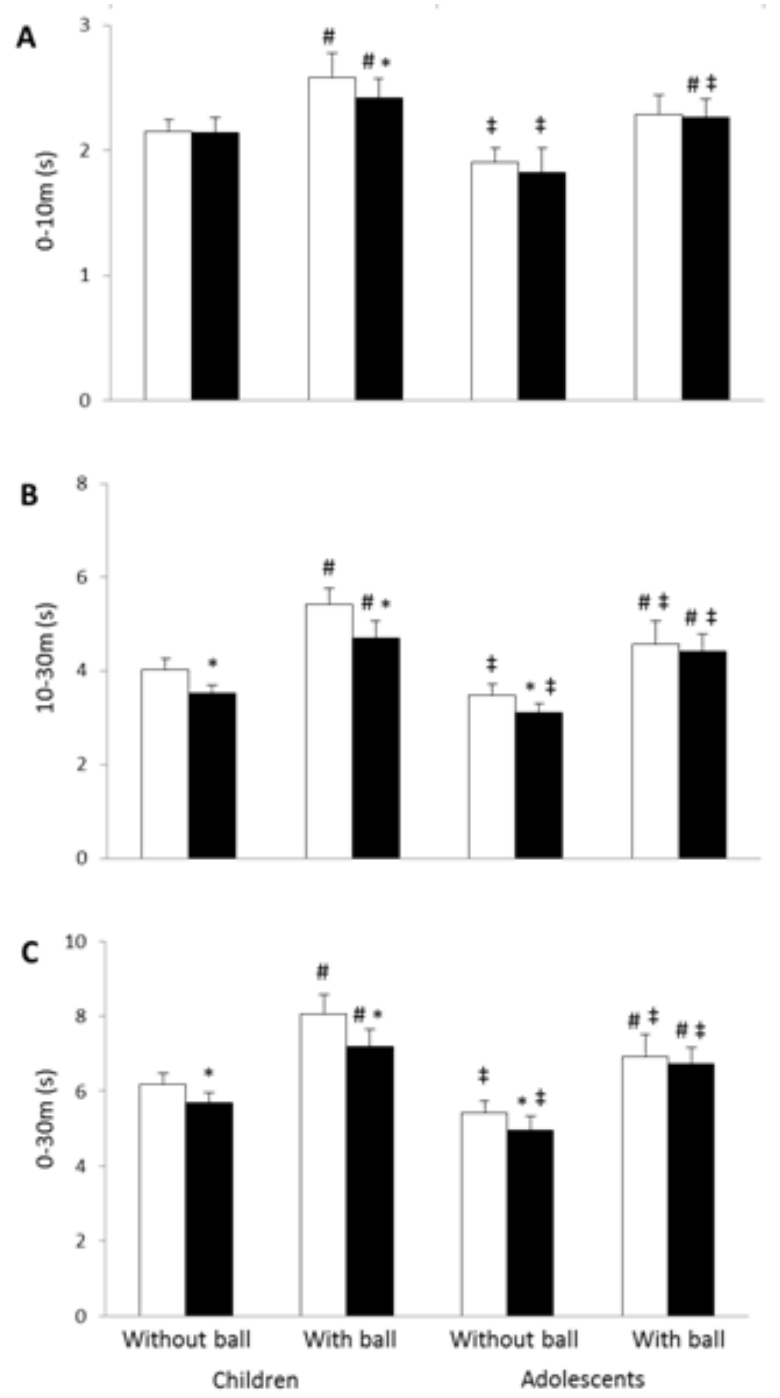

Figure 1. Speed performance for children and adolescents in running distances 0-10m (A), 10-30m (B) and 0-30m (C), with and without handling a ball on a natural (open bars) and an artificial (closed bars) grass. * significant difference between the two field surfaces. \# significant difference between with and without handling the ball. $\neq$ significant difference between children and adolescents
The better sprinting performance found on artificial grass is in line with previous reports revealing that soccer players can perform faster sprints, accelerations and decelerations on artificial compared to natural grass [10, 14, 15]. It was suggested that the greater force exerted on artificial compared to natural grass results in the faster movement ability [16]. Indeed, a greater reduction in peak torque was reported on the hamstrings after a game on natural compared to artificial grass [16].

In an early investigation in this research field it was found that the ball bounce and the ball roll were greater in artificial compared to natural grass [17]. Moreover, it was more difficult for the players to start, turn, and stop on artificial grass while handling the ball [17]. Similarly, in a more recent investigation using questionnaires, a negative overall impression for the artificial grass, poorer ball control, and greater subjective physical effort was reported by the players. This was despite the fact that the total distance, the intensity and the number of sprints were similar between natural and artificial grass [7]. On the contrary, in the present investigation children and adolescents exhibited either better or no different sprinting performance on the artificial grass compared to the natural grass. It is possible that the different age of the participants between the present study and the previous investigations explain the diverse outcomes.

It is clear that the higher speed of the ball developed on the artificial grass makes increases the difficulty of controlling it [7], leading to changes in the play style [18]. Indeed, players on artificial grass are frequently complaining for poorer ball control and greater subjective physical effort compared to the natural grass [7]. As a result, it is common for soccer players to perform less aggressive defense as the fewer sliding tackles suggests [7]. On other hand, no differences were observed in injury rate between natural and artificial grass [19]. Nevertheless, between the two field surfaces there are differences in the sites of injuries as well as in the type of tissue sustaining an injury [13]. For instance, the medial forefoot region had a significantly higher relative load on natural grass when compared to artificial grass while the central forefoot as well as the lesser toes exhibited higher pressure while cutting on the artificial grass surface compared to the natural grass [13]. In addition, in regards to the type of tissue injury, it was found a higher frequency of muscle tissue injury on artificial grass compared to natural grass [10]. More studies are required in order to reveal the differences in performance characteristics between juveniles and adults during a soccer training/game on artificial grass.

In the present investigation the recruitment of more age groups could give additional information regarding the effects of different turf surfaces on sprinting performance.

\section{Conclusions}

It is concluded that the sprinting performance of young soccer players on artificial grass is superior to natural grass. 
In fact, children ran faster on the artificial grass even when they had to handle the ball while adolescents ran faster on the artificial grass only without the ball. Therefore, caution should be paid when children play soccer on artificial grass because the ball is moving faster and greater skill is needed in order to avoid injuries. Considering that playing soccer on artificial grass affects playing style, more investigations in children and adolescences during a soccer game on different field surfaces are needed.

\section{References}

[1] C. Castagna, S. D'Ottavio, and G. Abt. Activity profile of young soccer players during actual match play. J Strength Cond Res. 2003, 17, 775-80.

[2] J. A. Harley, C. A. Barnes, M. Portas, R. Lovell, S. Barrett, D. Paul, and M. Weston. Motion analysis of match-play in elite U12 to U16 age-group soccer players. J Sports Sci. 2010, 28, 1391-7.

[3] C. Williams. Physiological demands of sprinting and multiple-sprint sports, R. J. Maughan. The Olympic Textbook of Science in Sport. Blackwell Publishing, 2009.

[4] A. Nummela, T. Keranen, and L. O. Mikkelsson. Factors related to top running speed and economy. Int J Sports Med. 2007, 28, 655-61.

[5] UEFA. FIFA quality concept: Handbook of test methods and requirements for artificial turf football surfaces, Nyon, Switzerland: UEFA, 2005.

[6] FIFA. FIFA quality concept for artificial turf quide, FIFA, Zurich, 2005.

[7] H. Andersson, B. Ekblom, and P. Krustrup. Elite football on artificial turf versus natural grass: movement patterns, technical standards, and player impressions. J Sports Sci. 2008, 26, 113-22.

[8] R. Di Michele, A. M. Di Renzo, S. Ammazzalorso, and F. Merni. Comparison of physiological responses to an incremental running test on treadmill, natural grass, and synthetic turf in young soccer players. J Strength Cond Res. 2009, 23, 939-45.
[9] A. Sassi, A. Stefanescu, P. Menaspa, A. Bosio, M. Riggio, and E. Rampinini. The cost of running on natural grass and artificial turf surfaces. J Strength Cond Res. 2011, 25, 606-11.

[10] M. M. Meyers, and B. Barnhill. Incidence, causes, and severity of high school football injuries on fieldturf versus natural grass. American Journal of Sports Medicine. 2004, 32 , 1626-38.

[11] R. J. Lysens, W. de Weerdt, and A. Nieuwboer. Factors associated with injury proneness. Sports Med. 1991, 12, 281-9.

[12] J. Orchard. Is there a relationship between ground and climatic conditions and injuries in football? Sports Med. 2002, 32, 419-32.

[13] K. R. Ford, N. A. Manson, B. J. Evans, G. D. Myer, R. C. Gwin, R. S. Heidt, Jr., and T. E. Hewett. Comparison of in-shoe foot loading patterns on natural grass and synthetic turf. J Sci Med Sport. 2006, 9, 433-40.

[14] G. L. Gains, A. N. Swedenhjelm, J. L. Mayhew, H. M. Bird, and J. J. Houser. Comparison of speed and agility performance of college football players on field turf and natural grass. J Strength Cond Res. 2010, 24, 2613-7.

[15] C. L. Stanitski, J. H. McMaster, and R. J. Ferguson. Synthetic turf and grass: a comparative study. J Sports Med. 1974, 2, 22-6.

[16] M. Nedelec, A. McCall, C. Carling, F. Le Gall, S. Berthoin, and G. Dupont. Physical performance and subjective ratings after a soccer-specific exercise simulation: comparison of natural grass versus artificial turf. J Sports Sci. 2013, 31, 529-36.

[17] W. Winterbottom. Artificial grass surfaces for association football. Report and recommendations. . London: Sport Council. 1985,

[18] T. Lindholm, P. Olsson, and P. Balsom. Fysiska och tekniska krav vid fotbollspel med olika antal spelare. . Svensk Idrottsforskning, Swedish Sports Research Magazine. 1998, 4, 30 - 1 .

[19] J. Ekstrand, T. Timpka, and M. Hagglund. Risk of injury in elite football played on artificial turf versus natural grass: a prospective two-cohort study. Br J Sports Med. 2006, 40, 975-80. 